This item was submitted to Loughborough's Research Repository by the author.

Items in Figshare are protected by copyright, with all rights reserved, unless otherwise indicated.

\title{
The HADRIAN approach to accessible transport
}

\section{PLEASE CITE THE PUBLISHED VERSION}

\section{PUBLISHER}

(C) IOS Press

\section{VERSION}

AM (Accepted Manuscript)

\section{PUBLISHER STATEMENT}

This work is made available according to the conditions of the Creative Commons Attribution-NonCommercialNoDerivatives 4.0 International (CC BY-NC-ND 4.0) licence. Full details of this licence are available at: https://creativecommons.org/licenses/by-nc-nd/4.0/

\section{LICENCE}

CC BY-NC-ND 4.0

\section{REPOSITORY RECORD}

Marshall, Russell, J. Mark Porter, Ruth Sims, Steve Summerskill, Diane E. Gyi, and Keith Case. 2019. "The HADRIAN Approach to Accessible Transport". figshare. https://hdl.handle.net/2134/5993. 


\title{
The HADRIAN Approach to Accessible Transport.
}

\author{
Russell Marshall ${ }^{\mathrm{a}}$, J Mark Porter ${ }^{\mathrm{a}}$, Ruth Sims ${ }^{\mathrm{a}}$, Steve Summerskill ${ }^{\mathrm{a}}$, Diane Gyi ${ }^{\mathrm{b}}$, Keith Case ${ }^{\mathrm{c}}$ \\ aDepartment of Design and Technology, Loughborough University, UK \\ bepartment of Human Sciences, Loughborough University, UK \\ 'Mechanical and Manufacturing Engineering, Loughborough University, UK \\ Address for Correspondence: \\ Russell Marshall \\ Department of Design and Technology \\ Loughborough University \\ Leicestershire \\ LE113TU \\ UK \\ Tel: +44 (0) $1509222669 \quad$ Fax +44 (0) 1509223999 \\ Email: r.marshall@lboro.ac.uk
}

\section{Abstract}

This paper describes research carried out at Loughborough University in the UK into the areas of 'design for all' and accessible transport. The research addresses two common needs for designers and ergonomists working towards developing more inclusive products and environments, namely data on users that is accessible, valid, and applicable and a means of utilising the data to assess the accessibility of designs during the early stages of development. HADRIAN is a computer-based inclusive design tool that has been developed to support designers in their efforts to develop products that meet the needs of a broader range of users. Currently HADRIAN is being expanded to support transport design. This includes data on an individual's ability to undertake a variety of transport-related tasks, such as vehicle ingress/egress, coping with uneven surfaces, steps, street furniture and complex pedestrian environments. The subsequent use of this data will be supported either through a task analysis system that will allow a designer to evaluate a design for a part of the transport infrastructure (ticket barrier, train carriage etc.), or alternatively allow the designer or an end user to evaluate a whole journey. The 'journey planner' feature of the HADRIAN tool will compare an individual's physical, cognitive and emotional abilities with the demands placed upon that individual by the mode(s) of transport available and the route options selected. It is envisaged that these developments will prove extremely useful to users, designers, planners and all those involved with transport use and implementation. 
Keywords: inclusive design, design for all, transport, human modelling, SAMMIE, HADRIAN

\section{Introduction}

There is growing evidence that products, services and environments should be 'designed for all' [1]. Nowhere is this clearer than in the area of transport, particularly public transport that, by its very nature, needs to be accessible to all people who may wish to use it.

Global populations are growing older, together with an increase in people with disabilities [2]. As such, the 'younger able-bodied' person is becoming less and less representative of the abilities, needs, and desires of the majority of people. This clearly provides a strong impetus, both morally and financially to design for the broadest range of consumers. Recognising this need, or opportunity, is important; however it is equally important to provide guidance and support for those who wish to design for all. Our approach has been to look at ways to integrate Design for All philosophy into existing good practice, such as the use of ergonomics design tools such as SAMMIE (System for Aiding Man Machine Interaction Evaluation).

SAMMIE is a computer aided human modelling system that represents a widely used tool to accommodate the needs of a broad range of differently sized and shaped people into the design of products [3]. SAMMIE has been successfully developed and employed in a large number of industrial, commercial and government projects through SAMMIE CAD Ltd., a UK Ergonomics Society Registered Design Consultancy [4]. However, the successful use of tools such as SAMMIE is often constrained by the need for 'expert' users. Many difficulties are encountered accessing the correct data, and then applying the data correctly. Designing from $5^{\text {th }}$ to $95^{\text {th }}$ percentile users (i.e. deliberately designing out people in the top or bottom $5 \%$ of size or ability) has become a de-facto standard and clearly highlights this issue [5]. It also 
illustrates that ergonomics tools can be used to support poor design decisions just as easily as good design decisions. These issues led to the development of HADRIAN.

HADRIAN (Human Anthropometric Data Requirements Investigation and Analysis) is a software tool, developed as part of the Engineering and Physical Research Council's (EPSRC - based in the UK) Design for All element of the EQUAL (Extending Quality Life) programme. The main focus of the work was to address two core concerns in the areas of design and ergonomics that were directly relevant to informing and supporting designers in their efforts to design for all [6]. These concerns relate to the need for designers to be able to predict multivariate accommodation, and can be summarised as follows [7]:

- The provision of relevant, accessible and holistic information on people of a broad range of size, shape, and ability

- A means of utilising the available information to assess the inclusiveness of a proposed design.

Assessment of design for all, or inclusive design problems is very complex. Even relatively simple products have a significant number of issues that must be addressed. Firstly there is the core functionality, which may require the user to view and interpret controls or instructions, to reach and operate the controls and to successfully complete a task. However, all of this is done in the context of some 'need' which may require understanding and evaluation of how the user accessed the product, where the product is located, and what might arise once the product has been used. All of these activities present multivariate accommodation problems for the designer. If any one element of these tasks cannot be completed by the user they are effectively 'designed out'.

In response to these concerns HADRIAN consists of two main elements. The first is a database consisting of physical and behavioural data on 100 individuals covering a broad 
range of ages and abilities (see Table 1). The sample is not representative and has been deliberately skewed towards the older and disabled population to offset the relatively well understood younger / able bodied population. Data are available on anthropometry, joint constraints, background information and also notes on any disabilities and problems experienced with activities of daily living [8].

\begin{tabular}{|l|l|}
\hline Age range & Even spread between18 and 89 years. 46 people are 60+ \\
\hline $\begin{array}{l}\text { Diagnosed } \\
\text { Impairments }\end{array}$ & $\begin{array}{l}59 \text { people have some form of impairment including: limb loss, } \\
\text { cerebral palsy, epilepsy, head injuries, knee problems, multiple, } \\
\text { sclerosis, arthritis, vision and hearing impairments, heart problems, } \\
\text { paraplegia, Parkinson's disease, stroke, and dyslexia, amongst } \\
\text { others }\end{array}$ \\
\hline Other impairments & $\begin{array}{l}\text { Of the } 43 \text { able bodied people } 5 \text { had young children and were } \\
\text { pushchair users and thus reported difficulties with using some forms } \\
\text { of transport and } 20 \text { were aged over } 60 \text { and had undiagnosed or minor } \\
\text { impairments associated with old age }\end{array}$ \\
\hline
\end{tabular}

Table 1.

A key feature of the database is how the data are presented. The database is effectively a catalogue of individuals, allowing the user to browse through the people in the database. This approach fosters empathy between the designer and the people who they are designing for, and attempts to minimise the dehumanizing effect of the virtual environment in which the design is being created. It also moves away from decisions to deliberately design out a proportion of the population based purely on the numbers.

Figure 1.

In order to address the issue with the applicability of available data HADRIAN also contains information with respect to some common tasks. The initial development of HADRIAN addressed localised design problems in response to surveys conducted with 50 older and disabled people [9]. The core of the survey examined how design could improve their quality of life. The two primary responses were: in being able to prepare meals for friends and 
family; and being able to use local transport. This lead to a focus on kitchen based tasks and a range of seating scenarios for initial data collection. Taking a pragmatic approach the data collection focussed on tasks that were sufficiently specific to be relevant to design needs, yet generically applicable so that we were not designing a kitchen design tool, or creating a system that required data on every possible task situation in order to be useful. In addition, ethical considerations and project resources required that we limit the scope of our study to a manageable size, both for the subjects and the researchers. Where possible the data collected reflects real-world application. Thus, comfort maximums were recorded to reflect what the subject would be likely to do in their own home where absolute maximums would not normally be used. In addition, tasks that represented hot loads such as lifting items into and out of the oven were performed using oven gloves to represent their affects on capability and behaviour.

Figure 2.

Task data stored within HADRIAN includes a success or a failure for each task element. In addition, the data not only records whether a task was completed, but also how it was completed. This behavioural element is a key part of the HADRIAN mechanism for predicting accurate postures in task situations. It could be argued that as long as the system predicts postures that the individual could adopt, the results would be valid and useful. However, older and disabled people often develop coping strategies for dealing with their reduced capability. These coping strategies make it much less predictable what an individual might do and subsequently what they might be capable of for any given task. Thus, we believe it is equally important to capture and then predict the capability, and behaviour, of an individual in a virtual fitting trial [10]. 


\section{Accessible transport}

The HADRIAN philosophy is now being expanded to address transport as part of the AUNTSUE (Accessibility and User Needs in Transport for Sustainable Urban Environments) consortium [11]. AUNT-SUE is part of the EPSRC's SUE programme. The consortium consists of UK academic institutions including London Metropolitan University, University College London and Loughborough University, together with local councils and other public and private bodies such as Camden Council, Hertfordshire Council, and the RNIB. The consortium's aim is to produce methodologies for sustainable policies and practices that will deliver effective socially inclusive design and operation of transport.

As part of the AUNT-SUE project, HADRIAN is being developed, to broaden the content of the database and to increase the functionality of the task analysis to incorporate transportrelated data. This addresses a key element in attempting to design for all and responds to the second most common response from our user surveys.

The new HADRIAN database will still contain 100 individuals though the sample has changed slightly to accommodate other potential transport users of interest that would not have been included as part of the first study. For example, individuals such as young mothers with children and pushchairs have been included. Whilst the people may not be older or disabled their particular situation can pose a problem for transport accessibility.

The complexity of transport related issues requires significant amounts of additional data to be collected as part of the AUNT-SUE study. These data include the capabilities and behaviour of people when entering or exiting from a range of public transport types. To collect these data an adjustable experimental rig was constructed that could be used to simulate entering and existing from UK rail, coach and bus vehicles with a range of step 
heights and handle locations. Participants were videoed traversing the rig at a range of step heights that represented what they were comfortable attempting.

To supplement, and potentially replace, traditional anthropometric measures the study has also been collecting whole body scanned data. Using a $[\mathrm{TC}]^{2}$ whole body scanning system, subjects have been scanned to capture their body form. The body scan provides a significant number of advantages including: the extraction of many more body measures than would be practicable using traditional methods, the ability to reprocess the data at a later date if additional measures are required without having to try to recall all the subjects, and a computer representation of the subject's body form which could be used for human modelling purposes in the future. However, this technology is still in development for this kind of application. The ability to recorded seated pose data is relatively under-developed, extremities such as the top of the head, hands and feet are not complete and so data on these areas must be captured separately. Of particular concern for applications such as HADRIAN is the ability to scan wheelchair users. If the user is capable of transferring to a standard stool then scans are possible. However, if the user must be scanned in their own chair more research needs to be done in order to make this a robust process.

Whilst the data outlined above enhance the database and improve its applicability to transport they are still only applicable to physical design problems. The initial version of HADRIAN and indeed, most ergonomics design and human modelling tools such as SAMMIE, work within the physical realm. However, as part of the AUNT-SUE project our aim is to expand the database beyond the physical into cognitive, emotional and sensory data associated with travel. These data cover the individual's ability to deal with tasks such as route planning, dealing with crowds and the effects of crowding on the transport design, understanding signs and other public information under conditions of high visual noise, issues with lighting, and the effects of perceptions of crime and personal safety. All of these elements are complex problems to understand and, in particular, to manipulate into a 
useable data resource. However, they are often some of the most fundamental issues when people are excluded. Thus, if we consider the design of an ATM, the ATM may be highly inclusive accommodating a broad range of users yet when placed in its operating environment it fails to be inclusive due to the dark and secluded location dissuading users from attempting to access it. Alternatively, a perfectly accessible train design may exclude users who cannot reach the train due to poor signage, or timetabling.

Part of our strategy to capture cognitive and emotional data is through the development of a Transport Activities Questionnaire. Participants are asked questions concerning: their physical abilities; any problems encountered when using trains, buses, trams, London-style taxi cabs and minicab taxis; their ability to walk distances, as well as issues surrounding taking luggage on the different transport modes; the types and frequency of journeys made; problems in using stairs, lifts or escalators; and difficulties in understanding timetables and signs. The questionnaire also includes a request for information about problems experienced in the local area. Any local areas that participants identified as causing problems, when travelling, are visited by the experimenters to provide quantitative data to supplement the reports from the participants. For example, this may range from measuring the force required to open a heavy shop door, to assessing the cognitive and emotional issues at a transport node (e.g. changing from a bus to the train, involving crossing busy roads, walking through empty or crowded public spaces with poor street lighting). In short, the questionnaire aims to provide information concerning issues that may arise at any point during the whole journey process.

\section{The whole journey approach}

As mentioned previously, HADRIAN's development has been targeted at addressing localised design problems (e.g. ATM, ticket barrier etc.). However, the concept of accessible transport is not solely related to any single piece of design, rather it concerns a network or system of designed elements. These designs could include everything from a flight of steps 
to a train carriage and yet they are all potential barriers to accessibility. This network is part of the transport infrastructure, combining a number of directly related, and indirectly related design problems that must be addressed holistically if accessible transport is taken in the context of the 'journey'.

The journey is part of our perception that accessible transport is there to enable users to travel from one place to another. To succeed in providing truly accessible transport we must be able to ensure that our door-to-door journey for example, from home to the doctor, from the bank to the theatre, or from the airport to a relative's house, is possible at every stage.

Figure 3.

As part of the AUNT-SUE consortium two test-bed sites have been identified: in the London Borough of Camden and in the County of Hertfordshire, both of which have council representatives on the project. As part of our whole journey approach we will use the testbeds to identify a number of relevant journeys from which we can collect data. The journeys will be based on observation and real world experience from people in the area and will include all of the accessible design elements that the individuals will have to deal with on those journeys. In particular we will identify the potential barriers faced by the people who make these journeys. These barriers may take many forms and are likely to include a range of: kerbs, pavements, slopes, steps, street furniture, cash dispensers, ticketing machines, lifts and escalators, toilets, transport types, and so on. Clearly, many of these potential barriers may be interacted with in the course of making a typical journey and if any one prevents the user from achieving a relatively small part of the overall task it may well prevent the journey from being possible. As part of this process AUNT-SUE partners have been recording a broad range of features within the testbed areas into a Geographical Information System (GIS). Layers of data on features such as drop-kerbs, pedestrian crossings, bus stops, etc are all recorded providing a richly detailed map of accessibility of the area [12]. 
It is intended that developments to the task analysis element of the HADRIAN system will also take this whole journey approach. Individual designs will still be the main focus of evaluation but they will be taken in the context of the journey and the designer will be able to evaluate the accessibility of a particular journey rather than have to consider each element in isolation. This approach should then provide a much more realistic evaluation of the social inclusiveness of any transport system.

\section{A journey planner}

One the most significant developments to the HADRIAN approach, currently under development, is a journey planner. Journey planners already exist in a number of forms. The most common are those associated with online booking of transport such as rail travel (e.g. Midland Mainline [13]. In addition to journey planners dedicated to one transport mode there are also journey planners flexible enough to assess a range of possible transport combinations to get a user from one location to another. An example of this type of journey planner is shown below.

Figure 4.

The Transport Direct [14] website provides an interface that allows a user wishing to explore a journey to enter details such as the location travelling from and the location travelling to, the dates and times of travel, in addition to the modes of transport to be searched (train, metro, bus, tram, car etc.), optional detours, number of changes and the like. The journey planner then searches all of the possible options and presents the user with a list. Each option can be explored in more detail. Figure 4 shows typical detail for a journey consisting of a underground / metro trip, followed by a walk, then train, another walk and finally a short bus ride. From this the user can explore alternatives, look at maps, and book tickets if desired. 
Whilst journey planners such as Transport Direct are flexible in searching multiple possibilities and in dealing with a range of user options they are limited in how well they reflect the real world and, in particular, the preferences and capabilities of the user. Transport Direct provide the ability to provide a walking speed and a maximum permitted walking time for the journey. However, this is clearly a compromise between complexity and accuracy. In reality the capability of an individual may make a significant difference to what is and is not possible with respect to the journey planner's recommendations. One example is that a user may be able to walk for multiple short periods that may add up to a long duration for the whole journey, as long as there is the ability to rest in-between. The system as it stands has no way of dealing with this level of extra information. Clearly, the user themselves can make a judgement about a suggested route, so the suggestion of an inappropriate option can still be useful. What is more of a problem is that any additional information about the user is not used in the search for a route and thus may mean that possible options have been discounted and not presented to the user in the final list. Whatever the outcome, if a route is suggested that then becomes relied upon by the user and that journey is unachievable or very difficult, either unaided or with support from others, then that person is likely to feel socially excluded.

It is proposed that HADRIAN will take the best practice and lessons learned from existing journey planners such as Transport Direct and combine this with our existing philosophy of using the rich source of data available in the HADRIAN database. In addition, the system will also allow new users to input their own data. The additional data available to the journey planner will allow routes to be suggested that account not only for the physical capabilities of a user but also factor in cognitive and emotional issues. For example, some people do not use trains because of difficulties experienced getting on and off. Clearly, information about their ability in this regard can be used to rule out the possibility of a train ride being part of a suggested route. However, some people would prefer not to walk through busy public areas 
or places with graffiti where they feel vulnerable; some experience problems finding their way on unfamiliar routes; some are reluctant to cross busy road junctions; and so on. Clearly these cognitive and emotional issues cannot be predicted by purely physical information.

The HADRIAN database contains information on users that will support the journey planner in suggesting routes that take these factors into account, allowing people to predict problems that they may experience before deciding to make the journey. Hopefully, a suitable alternative route and choice of transport mode(s) can be identified using the planner such that the task demands fall within the person's abilities and preferences.

Figure 5.

Figure 5 shows a mock-up of how the journey planner may look. The majority of information presented will be familiar, with route suggestions and the proposed modes of transport. What is novel about the HADRIAN approach is that the user will also be able to investigate each phase of the journey. Thus, the initial walk shown in Figure 5 is enhanced with some notes about that walk: the ground is flat with no steps, two pelican crossing will have to be negotiated, but there is a bus stop with a seat if necessary. It is predicted that trying to factor in some of the more subtle emotional issues involved in making a journey will be difficult. It may not be possible to include or exclude a possible transport mode for our route on the level of information available. Thus, it is likely that we will provide more detail about the nature of the route and allow the user to make the decision based upon their understanding of their own needs.

The investigation of journeys using the existing HADRIAN database will provide an invaluable tool to designers and planners of transport systems and parts of the infrastructure. It is believed that users such as local councils will find the system useful in supporting decision making. A council could use the system to identify the likely impact of proposed 
changes to the urban environment before implementation. This would then lead to greater confidence and also maximise the impact of any spending. Figure 5 also shows how the HADRIAN system could predict the likely accommodation of a suggested route.

The HADRIAN database will provide a useful resource for those looking to investigate what might happen to other people. Yet, it is clear that the journey planner will also need to be used by 'new' users whose data are not in the database. It is envisaged that a web-based planner could be made available. Users would need to complete an on-line questionnaire to provide relevant personal data on their body size (i.e. clothing sizes - a more accessible measure of size than having to measure limbs), general health, abilities and transport preferences.

Another issue of the proposed journey planner is the level of detail on the environment. It will be necessary to compile a database of the specific demands that would be placed on the traveller as a function of the exact geographic locations and the transport modes available for a particular journey. It is hoped that a pilot trial can be run in the testbed areas, with transport nodes, shopping areas, museums, theatres, cinemas and restaurants providing data for their surrounding areas (i.e. from the nearest bus stops, train station, taxi rank etc). The data could include, for example, distances by foot, details of steps/lifts/escalators, performance of street lighting/signposting, quality of the pavement/street surface, and perceived safety (e.g. ratings from a sample of people covering a range of ages and abilities) and objective safety (data on thefts, accidents, incidents etc). It is likely that a long term view would need to be taken, adopting a centrally managed, user driven process that employs many different strategies in order to successfully provide the level of detail necessary for the journey planner.

The final issue for the envisaged personalized journey planner will be dealing with day-to-day transport problems that will influence the selection of optimum routes and modes of travel, 
such as cancelled or delayed trains, road works or equipment failure. Our vision for the future would be for the journey planner to receive up-to-date information from transport service providers, local communities and individual travellers via the internet. The modernday mobile phone is now equipped with high resolution cameras and access to the internet; combined with a global positioning system (GPS), this will allow travellers to take photos of transport problems they are personally experiencing and upload them with a text or voice explanation to a specialist web site. This would enable real-time information to be accessed by the journey planner. To close the loop, travellers already on a planned journey could be contacted via their mobile phones with a revised journey plan to deal with these unforeseen problems.

\section{Conclusion}

Research into Design for All has led to the development of our design tool called HADRIAN. HADRIAN embodies the novel approach of maintaining ergonomics data as individuals and supplementing this with additional background information to provide empathy with the people being designed for. In addition, HADRIAN provides the ability to employ these individuals in virtual user trials providing a potentially quick and easy method for obtaining the kind of feedback you could expect from a real user trial. Furthermore, this feedback could be obtained during the early stages of design when the cost and time implications of finding a user group and building a full-size mock-up would be prohibitive.

HADRIAN is currently being developed towards supporting the design of accessible transport as part of the AUNT-SUE project. The developments include an expanded database incorporating transport related data, an enhanced task analysis tool, and a journey planner that will support both designers and end users in evaluating the accessibility of a whole journey. A key element in these developments is the type of data being collected and made available for evaluations. In addition to physical data, HADRIAN will be further expanded to 
incorporate cognitive, emotional and sensory information. This richness of data will then support evaluations of many common transport issues that are not purely related to a person's physical abilities. This will provide a tool that can be used to identify complex issues with any existing or proposed transport design that would not normally be possible without real user trials. 


\section{References}

[1] Coleman, R., Lebbon, C., Clarkson, J. and Keates S. (2003). From Margins to

Mainstream, In: Inclusive Design, design for the whole population, ed J. Clarkson et al, pp 125, Springer-Verlag. 2003

[2] WHO. (2007). World Heath Organisation: The world is fast ageing - have we noticed?. http://www.who.int/ageing/en/

[3] SAMMIE. (2007). SAMMIE CAD Ltd. http://www.sammiecad.com/

[4] Porter, J.M., Case, K. and Freer, M.T. (1999). Computer aided design and human models. In: Handbook of Occupational Ergonomics, Eds. Karwowski, W. and Marras, W., pp. 479-500, CRC Press LLC, Florida.

[5] Porter, J.M., Case, K., Marshall, R., Gyi, D.E. and Sims, R. (2004). 'Beyond Jack \& Jill': Designing for individuals within populations using HADRIAN. International Journal of Industrial Ergonomics, 33(3), pp. 249-264.

[6] Porter, J.M., Marshall, R., Sims, R.E., Gyi, D.E. and Case, K. (2003). HADRIAN: a human modelling CAD tool to promote 'design for all', Proceedings of INCLUDE 2003: inclusive design for society and business, Royal College of Art, London, 2003, pp. 222-228, CD-ROM.

[7] Marshall, R., Porter, J.M., Sims, R.E., Gyi, D.E. and Case, K. (2005). HADRIAN meets AUNT-SUE, Proceedings of INCLUDE 2005, INCLUDE 2005, Royal College of Art, London, UK, April 2005, pp. 1-7.

[8] Gyi, D.E., Sims, R.E., Porter, J.M., Marshall, R. and Case, K. (2004). Representing older and disabled people in virtual user trials; data collection methods, Applied Ergonomics, 35, 2004, pp-443-451.

[9] Oliver, R., Gyi, D.E., Porter, J.M., Marshall R. and Case K. (2001). A Survey of the Design Needs of Older and Disabled People. In: M. A. Hanson, ed. Contemporary Ergonomics. Proceedings of the Annual Ergonomics Society Conference, 10th-12th April, London: Taylor \& Francis, pp. 365-370. 
[10] Marshall, R., Case, K., Porter, J.M., Sims, R.E. and Gyi, D.E. (2004). Using Hadrian for Eliciting Virtual User Feedback in 'Design for All', Journal of Engineering Manufacture. IMECHE Proceedings Part B , 218(B9), 2004, pp. 1203-1210.

[11] AUNT-SUE. (2007). Accessibility and User Needs in Transport for Sustainable Urban Environments. http://www.aunt-sue.info/

[12] Azmin-Fouladi, N. and Evans, G. (2007). Designing the Inclusive Journey Environment, Proceedings of INCLUDE 2007, Royal College of Art, London, 2007, http://www.ektakta.com/include_proceedings/paper.php?ID=3_83 [13] Midland Mainline. (2007). http://www.midlandmainline.com [14] Transport Direct. (2007). Transport Direct: Britain's free online journey planner. www.transportdirect.info 


\section{Figure Captions:}

Figure 1. The HADRIAN database contains information on a broad range of individuals.

Figure 2. Data display from the HADRIAN database: showing anthropometry, task video clips, reach envelope data etc.

Figure 3. Potential barriers faced during a typical journey.

Figure 4. Example journey planner from Transport Direct [14].

Figure 5. HADRIAN journey planner mock-up showing predicted accommodation of suggested route. 


\section{Table Captions}

Table 1. A summary of the data available for the 100 people in the HADRIAN database. 
9. Figures

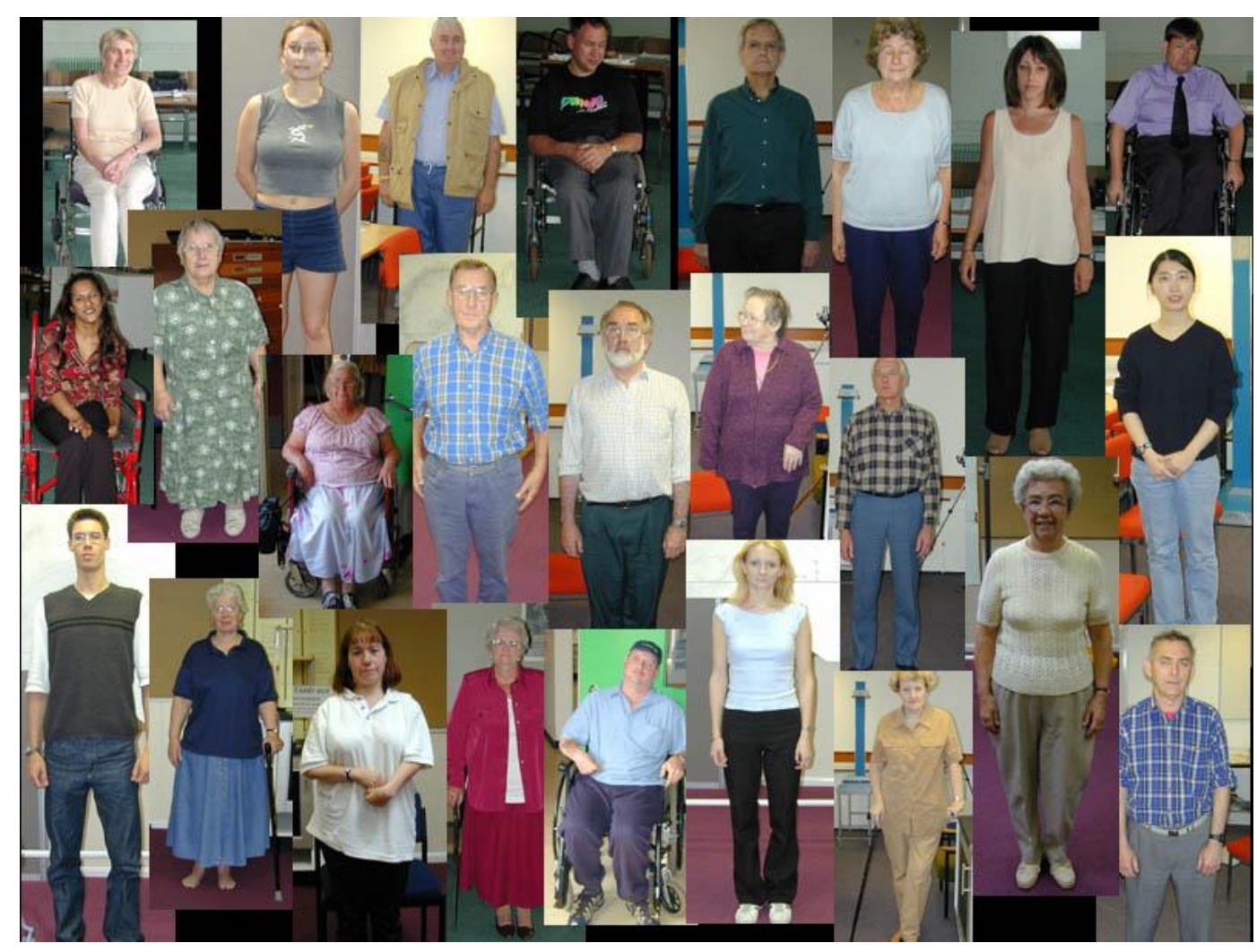

Figure 1. 


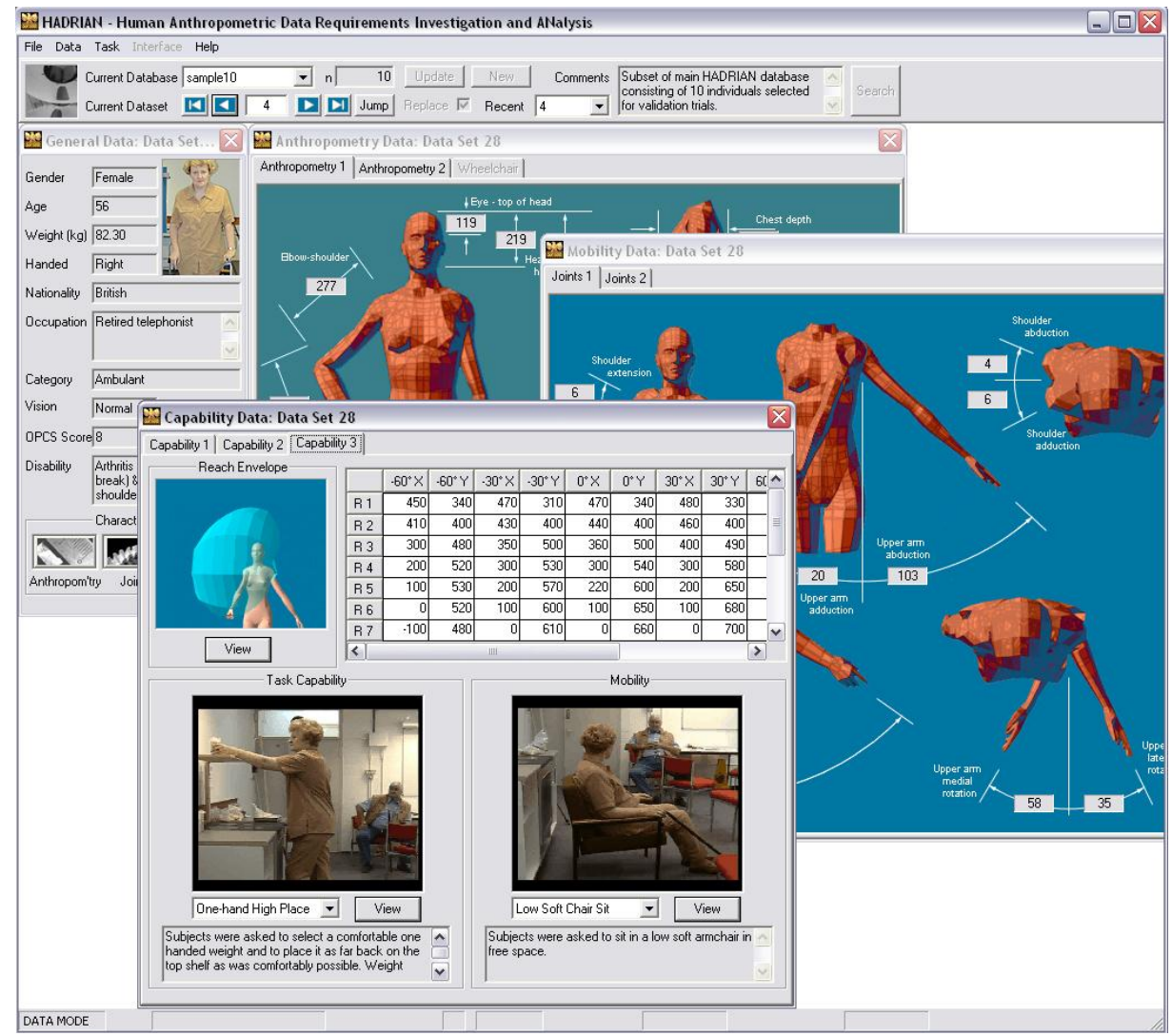

Figure 2. 


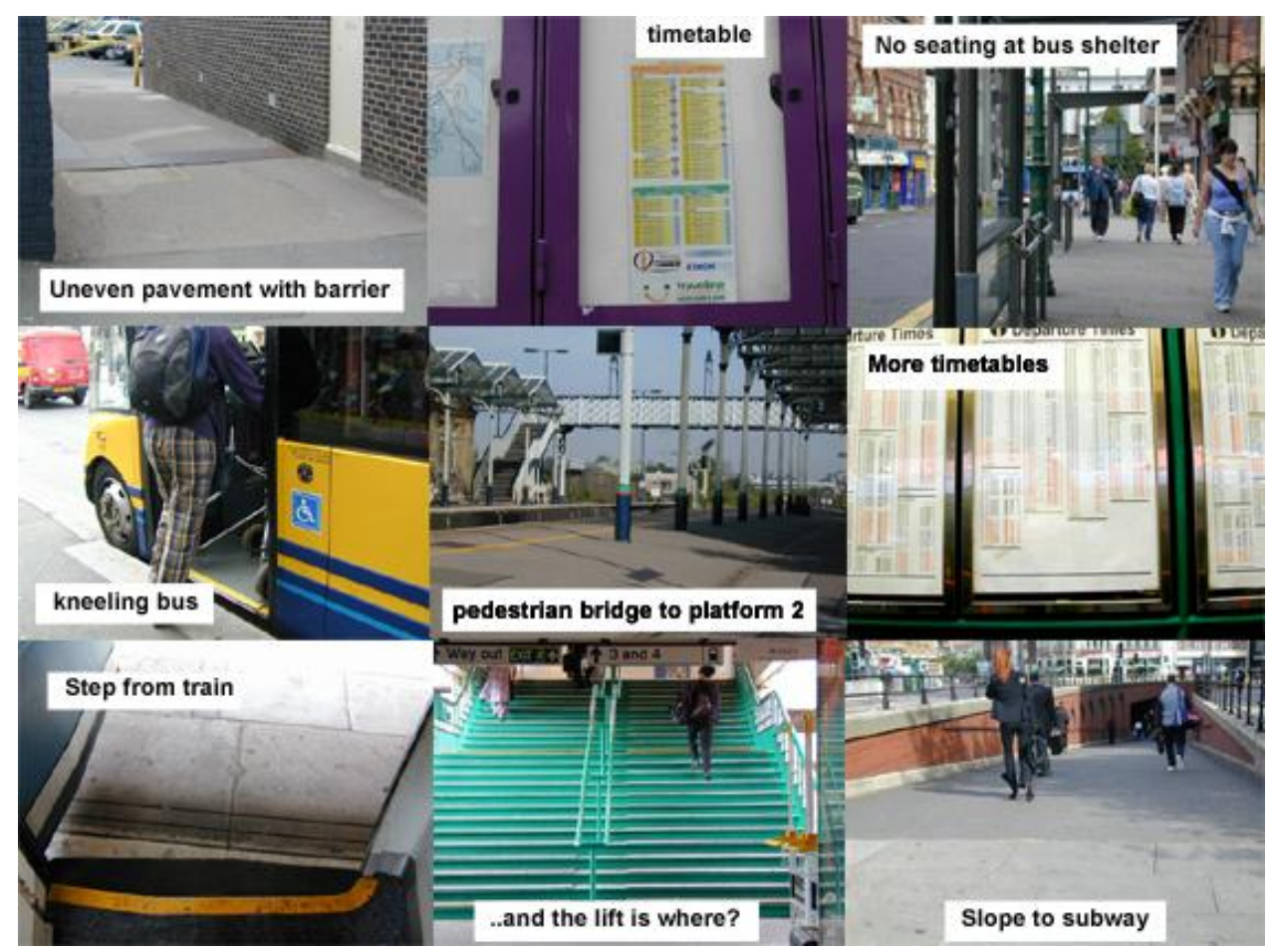

Figure 3. 


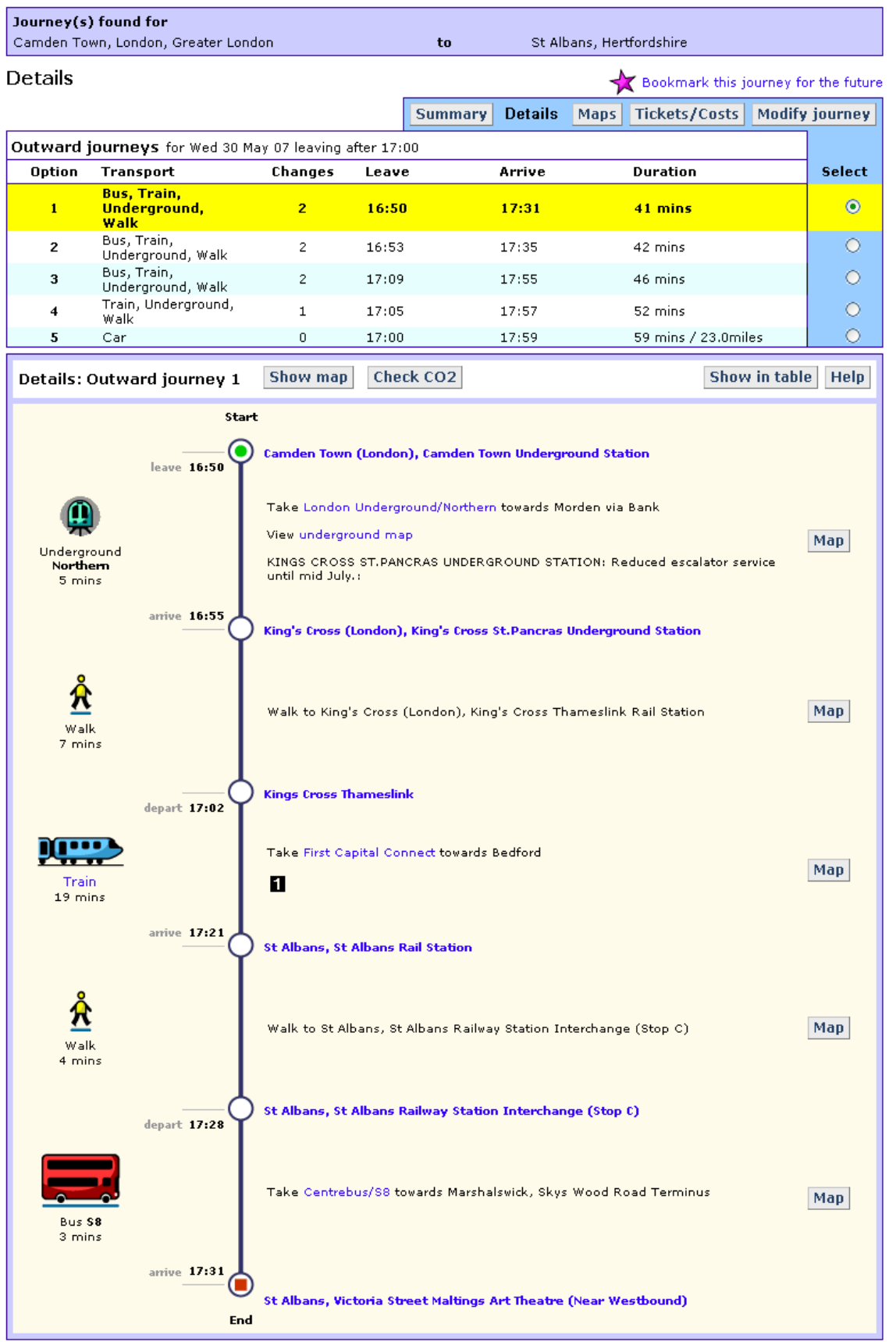

Figure 4. 


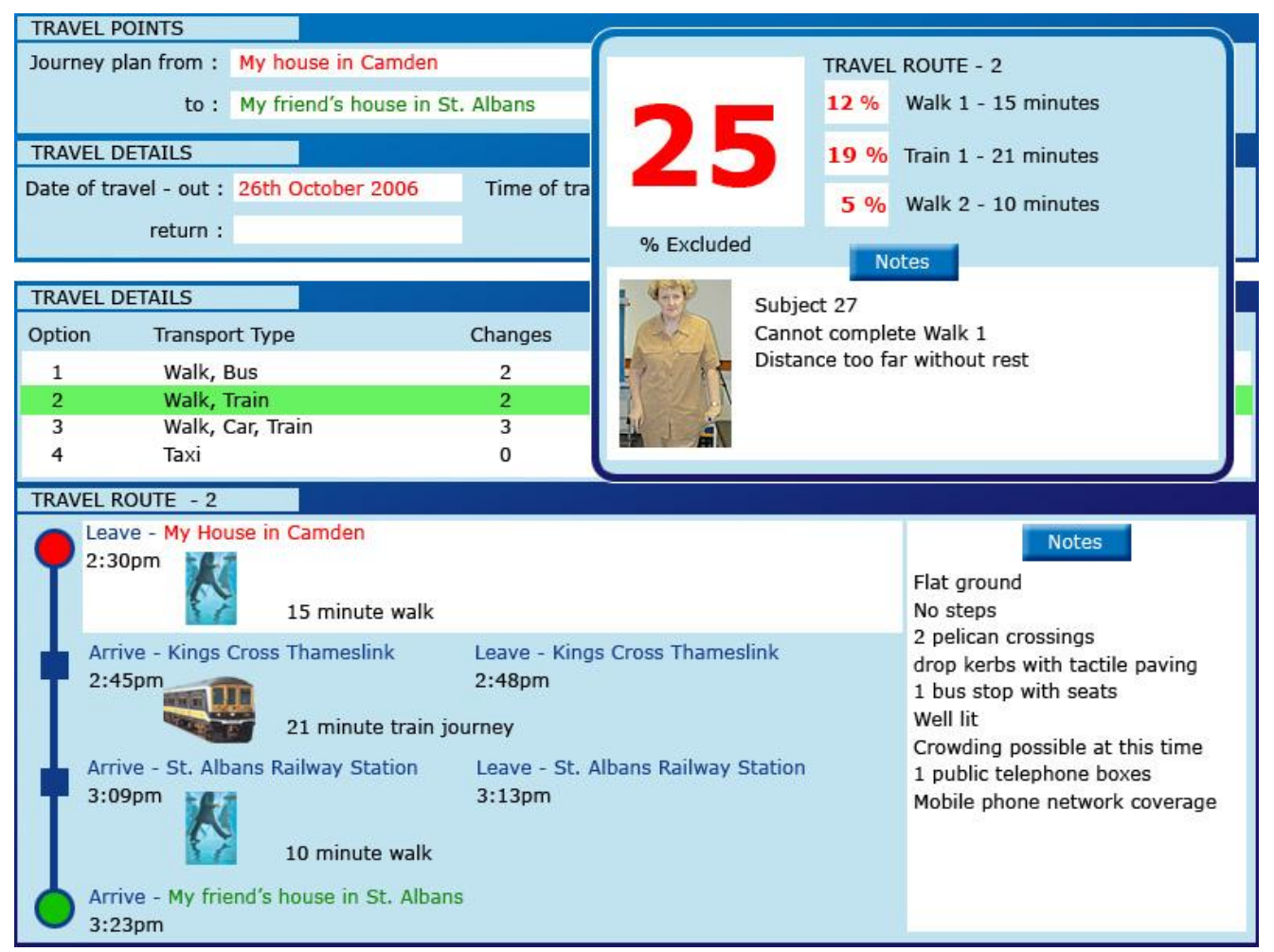

Figure 5. 